\title{
Cryptic striations in the upper mantle revealed by hafnium isotopes in southeast Indian ridge basalts
}

\author{
D. W. Graham ${ }^{1}$, J. Blichert-Toft ${ }^{2}$, C. J. Russo ${ }^{1}$, K. H. Rubin ${ }^{3}$ \& F. Albarède ${ }^{2}$
}

The Earth's mantle is isotopically heterogeneous on length scales ranging from centimetres to more than $10^{4}$ kilometres ${ }^{1,2}$. This heterogeneity originates from partial melt extraction and plate tectonic recycling, whereas stirring during mantle convection tends to reduce it. Here we show that mid-ocean ridge basalts from $2,000 \mathrm{~km}$ along the southeast Indian ridge (SEIR) display a bimodal hafnium isotopic distribution. This bimodality reveals the presence of ancient compositional striations (streaks) in the Indian Ocean upper mantle. The number density of the streaks is described by a Poisson distribution, with an average thickness of $\sim 40 \mathrm{~km}$. Such a distribution is anticipated for a well-stirred upper mantle, in which heterogeneity is continually introduced by plate tectonic recycling, and redistributed by viscous stretching and convective refolding.

The SEIR stretches from the Rodrigues Triple Junction $\left(25.6^{\circ} \mathrm{S}\right.$, $\left.70.1^{\circ} \mathrm{E}\right)$ to the Macquarie Triple Junction $\left(62^{\circ} \mathrm{S}, 151^{\circ} \mathrm{E}\right)$. Between $76^{\circ}-78^{\circ} \mathrm{E}$ it crosses the Amsterdam-St Paul (ASP) plateau, a pronounced bathymetric swell associated with relatively hot mantle upwelling beneath the Amsterdam and St Paul islands, while between $120^{\circ} \mathrm{E}$ and $128^{\circ} \mathrm{E}$ it crosses the Australian-Antarctic discordance $(\mathrm{AAD})$, a region of deep bathymetry $(>4,000 \mathrm{~m})$ associated with relatively cold mantle and low melt production ${ }^{3}$. Notably, over a distance of $\sim 2,500 \mathrm{~km}$, between $86^{\circ} \mathrm{E}$ and $120^{\circ} \mathrm{E}$, there is a regular eastward decrease in axial depth from 2,300 to $5,000 \mathrm{~m}$, and a morphological transition from axial high to axial valley due to decreasing melt production rate and crustal thickness. This depth gradient occurs at an intermediate and uniform spreading rate (70-75 $\mathrm{mm} \mathrm{yr}^{-1}$ full rate) and in the absence of large transform offsets and nearby mantle hotspots. The range in axial depth and ridge morphology is similar to the global range for spreading ridges away from hotspots, making the SEIR a regional-scale analogue of the 50,000-km-long global ocean ridge system. Previous work has established that the $\mathrm{He}, \mathrm{Pb}, \mathrm{Sr}$ and $\mathrm{Nd}$ isotope variations along the SEIR are primarily controlled by variation in the depth of melting of isotopically heterogeneous mantle $\mathrm{e}^{4-7}$. Also, all SEIR lavas west of the $\mathrm{AAD}$ are true 'Indian-type' on the basis of their elevated ${ }^{208} \mathrm{~Pb} /{ }^{206} \mathrm{~Pb}$ ratios $^{6}$.

New Hf isotope results have been obtained for 48 SEIR basalts previously analysed for $\mathrm{He}-\mathrm{Ne}-\mathrm{Ar}$ and $\mathrm{Pb}-\mathrm{Nd}-\mathrm{Sr}$ isotope compositions $^{4-7}$ (see Supplementary Table 1). All samples are fresh midocean ridge basalt (MORB) glasses that were microscopically handpicked to be free of surface alteration. Between 300 and $600 \mathrm{mg}$ of this glass was digested and the $\mathrm{Hf}$ separated using ultrapure reagents and following established techniques ${ }^{8}$. The new results show a +5.5 to +17.8 range in $\varepsilon \mathrm{Hf}$ (defined in Fig. 1). The extreme $\varepsilon \mathrm{Hf}$ values for the data presented here occur on the ASP plateau $(+5.5)$ and in the westernmost AAD $(+17.8)$, and are within the range of values measured previously in those areas ${ }^{9-12}$. Broadly speaking, Hf and $\mathrm{Nd}$ isotopes in our sample suite show the positive correlation typical of most oceanic basalts ${ }^{13}$. However, in detail the Hf isotope variations are not simply related to axial depth, ridge segmentation, MORB type or $\mathrm{Sr}-\mathrm{Nd}-\mathrm{Pb}-\mathrm{He}$ isotopic variations.

The striking attribute of this new data set, previously unobserved in MORBs, is the Hf isotopic bimodality for lavas erupted between $88^{\circ} \mathrm{E}$ and $110^{\circ} \mathrm{E}$ (Fig. 2). Over this $2,000-\mathrm{km}$ length of actively spreading ridge the two groupings show a 'gap' of about one epsilon unit $(\varepsilon \mathrm{Hf}=+9.5$ to +11.5 and +12.5 to +14.6 , respectively). This $\varepsilon$ Hf gap is significantly larger than the analytical uncertainty $(2 \sigma$ external precision is 0.3 epsilon units). Because our sample suite has a strong spatial resolution, the results suggest the presence of striations (streaks) in the upper mantle beneath the SEIR. The $\varepsilon$ Hf bimodality is not observed in other geochemical parameters, including $\mathrm{Nd}$ isotope composition, indicating that the streaks carry a cryptic memory of ancient chemical fractionation that is now only apparent in the time-integrated $\mathrm{Lu} / \mathrm{Hf}$ ratio. Because $\varepsilon \mathrm{Nd}$ along this section of the SEIR is not bimodal, Lu-Hf and Sm-Nd fractionation must have been decoupled at some point in the evolutionary history of the underlying upper mantle.

There are several possible origins for the bimodality in Hf isotopes and decoupling of $\mathrm{Nd}$ and $\mathrm{Hf}$ isotopes, most of which involve mixing with recycled mantle components (Fig. 3). One possibility is a remnant of primordial heterogeneity, perhaps resulting from the presence of a deep magma ocean. Given the efficiency of mantle convection in eradicating such remnants ${ }^{14}$, this explanation seems

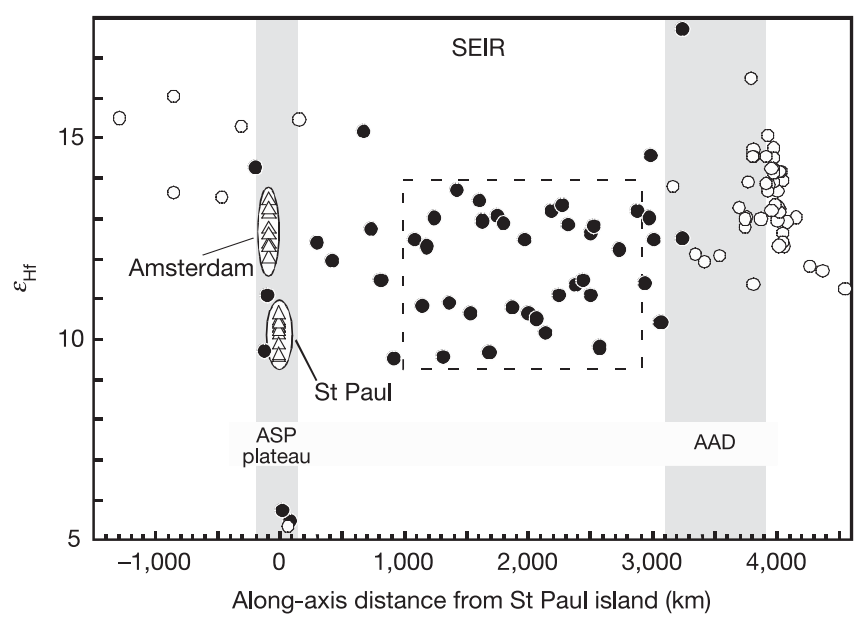

Figure 1 Along-axis variations in $\varepsilon \mathrm{Hf}$ for basalt glasses from the SEIR. $\varepsilon \mathrm{Hf}=\left({ }^{176} \mathrm{Hf} /{ }^{177} \mathrm{Hf}_{\text {measured }} /{ }^{176} \mathrm{Hf} /{ }^{177} \mathrm{Hf}_{\mathrm{BSE}}-1\right) \times 10^{4}$, where BSE is the bulk silicate Earth reference value of ${ }^{176} \mathrm{Hf} /{ }^{177} \mathrm{Hf}_{\mathrm{BSE}}=0.282772$ (ref. 16). New data from this study are shown as solid circles; other data are from refs 9-12. The dashed box outlines the area shown in Fig. 2a. 

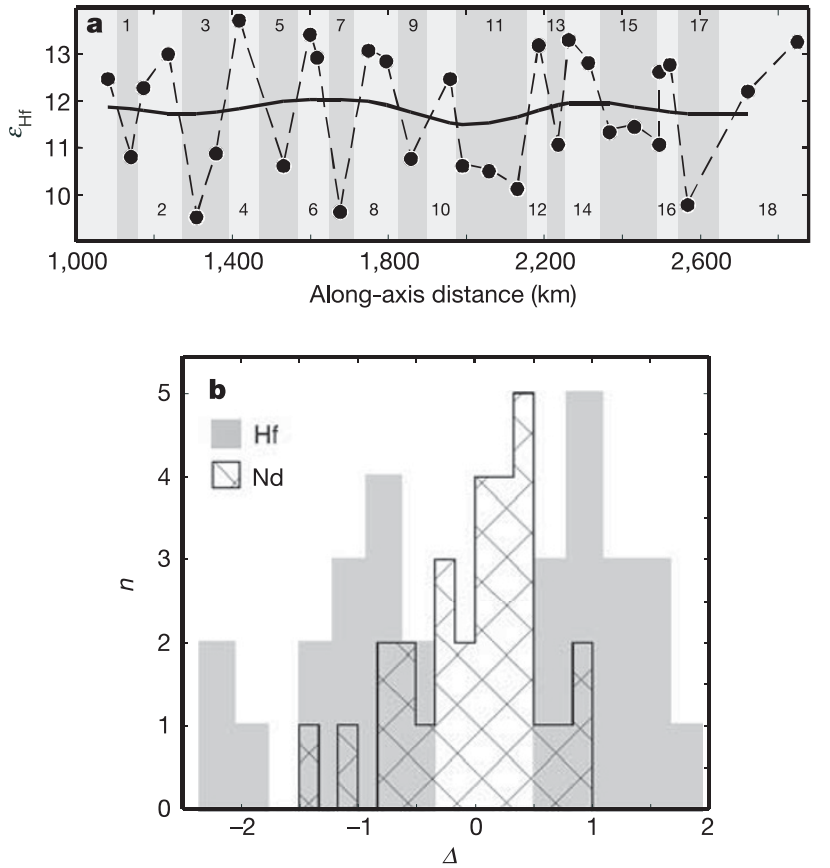

Figure 2 The $\mathrm{Hf}$ isotope bimodality. a, Detailed view of the bimodal $\varepsilon \mathrm{Hf}$ region between $88^{\circ} \mathrm{E}$ and $110^{\circ} \mathrm{E}$. The data clearly show two groupings separated by more than one epsilon unit, with high and low values delineated by the alternating stripes numbered 1 to 18 from west to east. The solid curve is a smoothed running mean using a gaussian spatial filter that has a standard deviation of $150 \mathrm{~km}$. $\mathbf{b}$, The histogram $(n=$ number of samples) shows the deviations $(\Delta)$ from the running mean in a. $\mathrm{Nd}$ isotopes have been treated similarly to the Hf isotope data and are shown for comparison. Student's $t$-test indicates that the probability of the Hf isotopes being drawn from a single population is $\ll 0.1 \%$.

unlikely, but it cannot be completely ruled out ${ }^{15}$. A second possibility is ancient melting that involved a variable amount of garnet restite, such as during komatiite formation ${ }^{16}$. The observed north-south $\varepsilon \mathrm{Hf}$ gradient in depleted Atlantic MORB and its relation to distance from the continents can be accounted for in this way ${ }^{17,18}$.

A third possibility involves mixing of different proportions of tectonically subducted components (altered oceanic crust/lithosphere, pelagic sediment and fluid-modified mantle wedge from subduction zones) with mantle peridotite. Fluid-modified, melt-depleted mantle wedge beneath subduction zones may display $\varepsilon \mathrm{Hf}$ lying above the Hf-Nd mantle array ${ }^{19}$. Variability in the mixing proportion of recycled sediment would produce a covariation in $\varepsilon \mathrm{Nd}-\varepsilon \mathrm{Hf}$, and is therefore unlikely, by itself, to account for the observed $\mathrm{Hf}$ isotope bimodality. However, variability in the proportion of pelagic sediment plus hydrothermally altered crust might produce the bimodality, if $\mathrm{Hf} / \mathrm{Nd}$ ratios in the recycled material range to both higher and lower values than $\mathrm{Hf} / \mathrm{Nd}$ in the ambient upper mantle (in which case mixing curves in $\mathrm{Hf}-\mathrm{Nd}$ isotopic space would diverge and could be strongly hyperbolic).

A fourth possibility is a difference in the mineralogic/lithologic make-up of the mantle source. For example, clinopyroxene in the residue of mantle melting can develop radiogenic $\varepsilon \mathrm{Hf}$ at relatively invariant $\varepsilon \mathrm{Nd}$ over $10^{8}$-year timescales, owing to its depletion in highfield-strength elements ${ }^{20}$. However, there is no evidence for covariation between Hf isotopes in SEIR basalts and potential indicators of modal clinopyroxene abundance or mantle source fertility, such as $\mathrm{Sc} / \mathrm{Nb}$ or $\mathrm{CaO} / \mathrm{Al}_{2} \mathrm{O}_{3}$ ratios. A fifth possibility is recycling of mid-crustal amphibolite or high-temperature granulite facies rocks in which rutile and iron-titanium oxides control $\mathrm{Lu} / \mathrm{Hf}$ and the extent of $\mathrm{Hf}$ depletion, as evidenced by significant $\mathrm{Lu} / \mathrm{Hf}-\mathrm{Sm} / \mathrm{Nd}$ decoupling in crustal xenoliths from southern African kimberlites ${ }^{21}$.

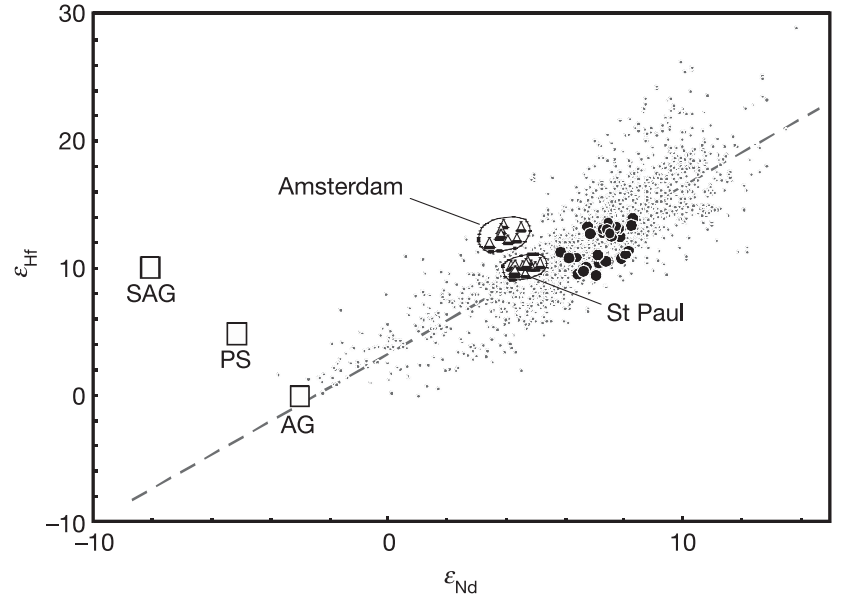

Figure 3 | Global $\varepsilon \mathrm{Hf}-\varepsilon \mathrm{Nd}$ correlation for $\sim 2,100$ oceanic basalts. Data are from the literature and from J.B.-T.'s unpublished database. The dashed line is the linear regression for all data $\left(\varepsilon \mathrm{Hf}=1.3 \varepsilon \mathrm{Nd}+3.3 ; R^{2}=0.70\right)$. The bimodal distribution of SEIR basalts is illustrated by the black circles; basalts from the Amsterdam and St Paul islands ${ }^{11}$, shown by the triangles, display a similar bimodality in $\varepsilon \mathrm{Hf}$. Examples of potential recycled endmembers that may be involved in mantle mixing are included for comparison $(\mathrm{AG}=$ Australian granulite, $\mathrm{PS}=$ pelagic sediment, $\mathrm{SAG}=$ South African granulite; for example, see ref. 23).

Lastly, garnet in some cratonic peridotites from South African kimberlites shows $\varepsilon \mathrm{Hf}=+200$ to +400 , while $\varepsilon \mathrm{Nd}$ ranges only between 0 and +15 (ref. 22). The significant potential for $\mathrm{Hf}-\mathrm{Nd}$ isotopic decoupling by recycling of continental lithospheric mantle may account for the isotopic variations observed along the southwest Indian ridge $e^{23}$.

Regardless of their exact origin, the different mantle source regions beneath the SEIR sampled by the MORB Hf isotope bimodality have primarily witnessed a history of coupled Lu/Hf-Sm/Nd fractionation similar to most of the oceanic mantle, because the bimodal populations lie close to the modern $\varepsilon \mathrm{Hf}-\varepsilon \mathrm{Nd}$ array for oceanic basalts and as a group adhere to the overall trend in this diagram (Fig. 3).

Spatially, the streaks defined by the Hf isotope bimodality are well described as a Poisson distribution, in which the number of $\mathrm{Hf}$ isotope 'toggles' between the two groupings is proportional to the length of ridge sampled (Fig. 4a). A Poisson distribution describes the total number of independent events that occur within a specified interval for a fixed mean value of the 'arrival rate'; it is characterized by a number of events proportional to the length of the observation span (for example, as exemplified by radioactivity). The number of Hf isotope 'toggles' in SEIR basalts closely follows this prediction over a ridge length of $>2,000 \mathrm{~km}$, as expected for a Poisson distribution of cryptic streaks in the underlying mantle. Moreover, when the number of striation boundaries follows a Poisson distribution, the intervals between boundaries (that is, the striation thicknesses) follow an exponential distribution, as observed in the current data set (Fig. 4b). The Hf isotope 'toggles' are not as well-discerned outside the $88^{\circ} \mathrm{E}$ to $110^{\circ} \mathrm{E}$ section of the SEIR, and seem to be absent where the geodynamic setting is more complex, such as on top of the ASP plateau and within the AAD. Given the sampling density along the SEIR, the mean thickness of the striations in the underlying mantle appears to be $\sim 40 \mathrm{~km}$ (Fig. $4 \mathrm{a}$ inset).

Let us define a geochemical heterogeneity as a point on the boundary between two types of mantle, for example, a mantle residue of partial melting versus recycled crust or lithosphere. A Poisson distribution of geochemical heterogeneities should be anticipated as the natural consequence of a well-stirred upper mantle in which heterogeneities are continually created by tectonic recycling and redistributed by convective stretching and refolding. The mean striation thickness is therefore a useful parameter for quantifying 

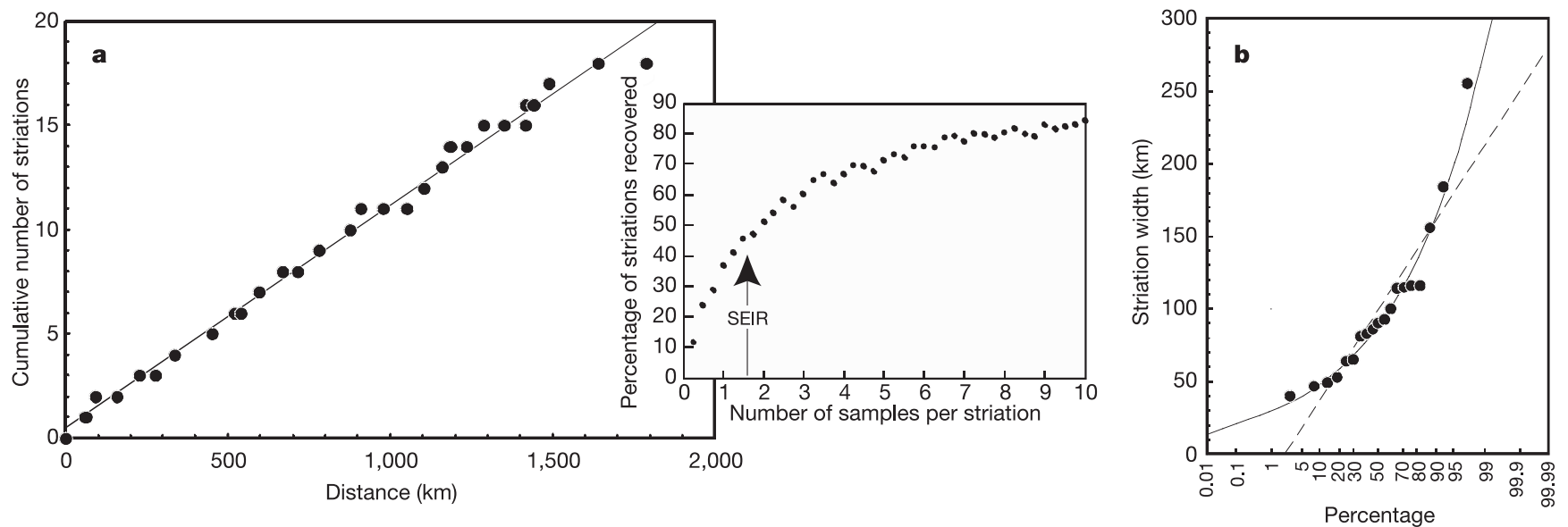

Figure 4 Poisson character of upper mantle streaks beneath the SEIR. a, Cumulative number of $\mathrm{Hf}$ isotopic striations versus distance (in kilometres) along the SEIR. The line shown is a linear regression $\left(y=0.0107 x+0.487, R^{2}=0.992, n=29 ; 1 \sigma\right.$ uncertainties on the slope and intercept are 0.00099 and 0.988 , respectively). The mean thickness of the striations, based on the slope of this diagram, would be $93 \mathrm{~km}( \pm 9 \mathrm{~km}, 1 \sigma)$ The inset illustrates how the inferred mean thickness of the striations is affected by sampling density. A large population with a uniform density for the probability of a transition between two different mantle 'flavours' has been approximated by 1,000 points spread randomly along a line. The distance between two consecutive points represents the thickness of an individual striation. This model has an exponential distribution of striation thicknesses, consistent with the observed relationship between cumulative

mantle strain rate $e^{24}$. Strain rates associated with mantle convection are of the order of $10^{-15} \mathrm{~s}^{-1}$ (ref. 25). After 40 million years (Myr), recycled material would have been stretched and reduced to about $50 \%$ of its original thickness via shear strain, and after $300 \mathrm{Myr}$ to about $10 \%$. (Corresponding timescales for stretching by normal strain are shorter, $\sim 25$ and $80 \mathrm{Myr}$, respectively; Supplementary Fig. 1.)

The timescale of $300 \mathrm{Myr}$ is similar to that inferred from comparative $\mathrm{U}-\mathrm{Pb}, \mathrm{Sm}-\mathrm{Nd}$ and $\mathrm{Rb}-\mathrm{Sr}$ isotope systematics of enriched and depleted MORB worldwide. This timescale potentially represents a convective cycling time within the mantle, either for oceanic lithosphere and metasomatized mantle subducted beneath island arcs or for continental lithosphere delaminated during rifting, to the eventual resampling by partial melting beneath mid-ocean ridges $^{26-28}$. Notably, the $\mathrm{Pb}, \mathrm{Nd}, \mathrm{Sr}$ and $\mathrm{Hf}$ isotopes in SEIR basalts are correlated with their respective parent/daughter ratios, and each of these correlations also imply 'ages' of 200-400 Myr (ref. 6 and Supplementary Fig. 2). However, these age estimates have large uncertainties, and probably represent minimum values because the slopes of the correlations could also have been affected by varying $\mathrm{U} / \mathrm{Pb}, \mathrm{Sm} / \mathrm{Nd}, \mathrm{Rb} / \mathrm{Sr}$ and $\mathrm{Lu} / \mathrm{Hf}$ ratios during melting.

The narrow range of $\varepsilon \mathrm{Hf}$ of $<5$ units in the bimodal region makes it currently impossible to discriminate between the possible origins of the streaks, because diagnostic geochemical signatures associated with the small extent of Lu/Hf-Sm/Nd decoupling are extremely weak in this sample suite. Nevertheless, the fact that the Amsterdam and St Paul islands display the same Hf isotope bimodality ${ }^{11}$ as the SEIR MORBs studied here (Fig. 3) suggests a significant role for upwelling plumes in convective dispersion and refolding of such mantle streaks, and is further evidence that regions of the upper mantle far from any active hotspot influence still retain a record of past pollution by mantle plumes ${ }^{29}$.

The isotopic compositions of mantle-derived materials provide constraints on crust/mantle differentiation and planetary evolution, while their spatial distribution is fundamentally linked to mantle dynamics. The Hf isotope bimodality along the SEIR represents the number of transitions and distance. As expected, the proportion of striations recovered during sampling increases as the sampling density (that is, number of samples per striation) increases. Because the sampling density along the SEIR has 1.6 samples per striation, about $40 \%$ of the striations present in the underlying mantle have been sampled, indicating that the true mean thickness of the striations is $\sim 40 \mathrm{~km}$. b, Probability diagram of the width (thickness) of the Hf isotopic striations. The $x$ axis shows the percentage of striation widths (normalized to a normal probability distribution) whose value is less than the respective value of the $y$-axis data point. The solid curve is an exponential fit $(y=89.71 \exp [0.476 x]$, $\left.R^{2}=0.971\right)$ and the dashed line is a linear fit $(y=100.4+48.97 x$, $R^{2}=0.86$ ). This good exponential relationship is consistent with a Poisson distribution for the number density of upper mantle striations.

first observational evidence that a Poisson distribution of heterogeneous streaks characterizes large sections of the upper mantle. We speculate that this distribution is more easily recognized along the SEIR than along other sections of the mid-ocean ridge system, because the SEIR is uncomplicated by the effects of nearby mantle hotspots, continental land masses, or large fracture zone offsets. Striation thickness distributions in realistic, time-periodic flows of viscous fluids, such as those appropriately describing aspects of the Earth's mantle, are extremely difficult to model numerically given the computational state-of-the-art. However, striation thickness distributions can be accurately predicted from a knowledge of the stretching values ${ }^{30}$. A Poisson distribution of mantle heterogeneities, and the associated exponential distribution of striation thicknesses, is a fundamental mantle property that should be taken into account in forthcoming models of mantle convection and rheology.

\section{Received 3 August 2005; accepted 12 January 2006.}

1. Hart, S. R. A large-scale isotope anomaly in the Southern Hemisphere mantle. Nature 309, 753-757 (1984).

2. Allègre, C. J. \& Turcotte, D. L. Implications of a two-component marble-cake mantle. Nature 323, 123-127 (1986).

3. Sempéré, J.-C., Palmer, J., Christie, D., Morgan, J. P. \& Shor, A. AustralianAntarctic discordance. Geology 19, 429-432 (1991).

4. Graham, D. W., Lupton, J. E., Spera, F. J. \& Christie, D. M. Upper mantle dynamics revealed by helium isotope variations along the southeast Indian ridge. Nature 409, 701-703 (2001).

5. Nicolaysen, K. E. The Cretaceous to Recent History of the Southeastern Indian Ocean: The Role of Mantle Plumes Examined by the Geochronology and Sr, Nd, Pb and He Isotopic Geochemistry. 1-274, PhD dissertation, Mass. Inst. of Technol. (2001)

6. Mahoney, J. J. et al. Between a hot spot and cold spot: isotopic variation in the Southeast Indian Ridge asthenosphere, $86^{\circ}-118^{\circ}$ E. J. Petrol. 43, 1155-1176 (2002).

7. Burnard, P., Graham, D. W. \& Farley, K. A. Fractionation of noble gases (He, Ar) during MORB mantle melting: a case study on the Southeast Indian Ridge. Earth Planet. Sci. Lett. 227, 457-472 (2004).

8. Blichert-Toft, J., Chauvel, C. \& Albarède, F. Separation of Hf and Lu for highprecision isotope analysis of rock samples by magnetic sector-multiple collector ICP-MS. Contrib. Mineral. Petrol. 127, 248-260 (1997). 
9. Chauvel, C. \& Blichert-Toft, J. A hafnium and trace element perspective on melting of the depleted mantle. Earth Planet. Sci. Lett. 190, 137-151 (2001).

10. Kempton, P. L., Pearce, J. A., Barry, T. L., Langmuir, C. H. \& Christie, D. M. $\mathrm{Sr}-\mathrm{Nd}$-Pb-Hf isotope results from ODP Leg 187: evidence for mantle dynamics of the Australian-Antarctic discordance and origin of the Indian MORB source. Geochem. Geophys. Geosyst. 3, doi:10/1029/2002GC000320 (2002).

11. Doucet, S., Weis, D., Scoates, J. S., Debaille, V. \& Giret, A. Geochemical and $\mathrm{Hf}-\mathrm{Pb}-\mathrm{Sr}$-Nd isotopic constraints on the origin of the Amsterdam-St. Paul (Indian Ocean) hotspot basalts. Earth Planet. Sci. Lett. 28, 179-195 (2004).

12. Hanan, B., Blichert-Toft, J., Pyle, D. G. \& Christie, D. M. Contrasting origins of the upper mantle revealed by hafnium and lead isotopes from the Southeast Indian Ridge. Nature 432, 91-94 (2004).

13. Salters, V. J. M. \& White, W. M. Hf isotope constraints on mantle evolution Chem. Geol. 145, 447-460 (1998).

14. Blichert-Toft, J. \& Albarède, F. Short-lived chemical heterogeneities in the Archaean mantle with implications for mantle convection. Science 263, 1593-1596 (1994).

15. Albarède, F. in Structure, Composition and Evolution of the Earth's Mantle (eds van der Hilst, R. D., Bass, J., Matas, J. \& Trampert, J.) 27-46 (Geophys. Monogr. 160, American Geophysical Union, Washington DC, 2005).

16. Blichert-Toft, J., Arndt, N. \& Gruau, G. Hf isotope measurements on Barberton komatiites: effects of incomplete sample dissolution and importance for primary and secondary magmatic signatures. Chem. Geol. 207, 261-275 (2004).

17. Andres, M., Blichert-Toft, J. \& Schilling, J.-G. Nature of the depleted upper mantle beneath the Atlantic: evidence from $\mathrm{Hf}$ isotopes in normal mid-ocean ridge basalts from $79^{\circ} \mathrm{N}$ to $55^{\circ} \mathrm{S}$. Earth Planet. Sci. Lett. 225, 89-103 (2004).

18. Blichert-Toft, J. et al. Geochemical segmentation of the Mid-Atlantic Ridge north of Iceland and ridge-hotspot interaction in the North Atlantic. Geochem. Geophys. Geosyst. 6, doi:10.1029/2004GC000788 (2005).

19. Woodhead, J. D., Hergt, J. M., Davidson, J. P. \& Eggins, S. M. Hafnium isotope evidence for 'conservative' element mobility during subduction zone processes. Earth Planet. Sci. Lett. 192, 331-346 (2001)

20. Salters, V. J. M. \& Zindler, A. Extreme ${ }^{176} \mathrm{Hf} /{ }^{177} \mathrm{Hf}$ in the sub-oceanic mantle. Earth Planet. Sci. Lett. 129, 13-30 (1995).

21. Schmitz, M. D., Vervoort, J. D., Bowring, S. A. \& Patchett, P. J. Decoupling of the $\mathrm{Lu}-\mathrm{Hf}$ and $\mathrm{Sm}-\mathrm{Nd}$ isotope systems during evolution of granulitic lower crust beneath southern Africa. Geology 32, 405-408 (2004).

22. Bedini, R. M., Blichert-Toft, J., Boyet, M. \& Albarède, F. Isotopic constraints on the cooling of the continental lithosphere. Earth Planet. Sci. Lett. 223, 99-111 (2004).
23. Janney, P. E., le Roex, A. P. \& Carlson, R. W. Hafnium isotope and trace element constraints on the nature of mantle heterogeneity beneath the central Southwest Indian Ridge ( $13^{\circ} \mathrm{E}$ to $\left.47^{\circ} \mathrm{E}\right)$. J. Petrol. 46, 2427-2464 (2005).

24. Olson, P. L., Yuen, D. A. \& Balsiger, D. S. Mixing of passive heterogeneities by mantle convection. J. Geophys. Res. 89, 425-436 (1984).

25. Schubert, G., Turcotte, D. L. \& Olson, P. Mantle Convection in the Earth and Planets 1-940 (Cambridge Univ. Press, Cambridge, Massachusetts, 2001).

26. Allègre, C. J. \& Lewin, E. Isotopic systems and stirring times of the Earth's mantle. Earth Planet. Sci. Lett. 136, 629-646 (1995).

27. Albarède, F. Radiogenic ingrowth in systems with multiple reservoirs: applications to the differentiation of the mantle-crust system. Earth Planet. Sci. Lett. 189, 59-73 (2001)

28. Donnelly, K. E., Goldstein, S. L., Langmuir, C. H. \& Spiegelman, M. Origin of enriched ocean ridge basalts and implications for mantle dynamics. Earth Planet. Sci. Lett. 226, 347-366 (2004).

29. Hanan, B. B., Kingsley, R. H. \& Schilling, J.-G. Pb isotope evidence in the South Atlantic for migrating ridge-hotspot interactions. Nature 322, 137-144 (1986)

30. Muzzio, F. J., Alvarez, M. M., Cerbelli, S., Giona, M. \& Adrover, A. The intermaterial area density generated by time- and spatially periodic $2 \mathrm{D}$ chaotic flows. Chem. Eng. Sci. 35, 1497-1508 (2000)

Supplementary Information is linked to the online version of the paper at www.nature.com/nature.

Acknowledgements D.W.G. thanks A. Bouvier, A. Agranier, P. Beck, F. Moynier K. Koga and E. Koga for their help and hospitality during two extended visits to Lyon. We thank P. Telouk for his help with the P54 mass spectrometer. D. Christie, B. Hanan, K. Johnson, J. Mahoney and D. Pyle provided help on many aspects of SEIR geochemistry. N. Pisias provided insight into some of the nuances of statistical distributions. D.W.G., C.J.R. and K.H.R. were supported by the Marine Geology division of the NSF, and J.B.-T. and F.A. by the French Institut National des Sciences de I'Univers.

Author Contributions D.W.G. and J.B.-T. performed the Hf isotope measurements. All authors contributed to data analysis.

Author Information Reprints and permissions information is available at npg.nature.com/reprintsandpermissions. The authors declare no competing financial interests. Correspondence and requests for materials should be addressed to D.W.G. (dgraham@coas.oregonstate.edu). 